\title{
REGISTRO DE FASCIOLOSE HEPÁTICA EM EQUINO DE SANTA CATARINA, BRASIL
}

\author{
SILVINO NUERNBERG ${ }^{a}$ \\ NICOLAU MAUÉS SERRA FREIRE ${ }^{b}$
}

NUERNBERG, S. \& FREIRE, N.M. da S. Registro da Fasciolose hepática em equino de Santa Catarina, Brazil. Semina: Ci. Agr., Londrina, v. 13, n. 1,p. $41-43$, mar. 1992.

\section{RESUMO}

Utilizando a técnica de filtração seqüencial em tamis com 250, 150, 80 e 37 um de malha, eapós quatorze anos de investigaçāo no Estado de Santa Catarina, comprovou-se o parasitismo natural por Fasciola hepasica de um eqüino mestiço fêmea, com 7 a 8 anos de idade, entre 132 eqüinos examinados, no Vale do Itajal.

Esse es o primeiro registro de Fasciolosa equina em Santa Catarina.

PALAVRAS-CHAVE: Fasciola hepatica, Eqüino, exame de fezes, Vale do ltajal.

\section{1 - INTRODUÇĀo}

A partir de janeiro de 1977, em trabalho sistemático de exames de fezes para diagnóstico de parasitoses de animais domésticos, o Laboratório de Diagnóstico do Laboratório de Apoio à Pesquisa Animal, LAPA/SC vem catalogando o material com comprovaçāo de parasitismo por Fasciola hepatica. Dessa atividade, SERRA FREIRE \& NUERNBERG ${ }^{13}$ relataram a dispersāo geopolítica da ocorrência dessa espécie de trematodeo no Estado, registrando a comprovaçāo parasitária em ruminantes. Nesse trabalho os autores destacaram que $27,86 \%$ dos bovinos, $24,72 \%$ dos bubalinos, $16,92 \%$ dos ovinos e $15,66 \%$ dos caprinos apresentavam parasitismo natural por F. hepatica, para um total de 13.762 amostras de fezes examinadas. Esses autores ainda demonstraram que - Vale do Itajaf na Bacia Hidrográfica do Sudeste é uma regiāo endêmica dessa helmintose.

De acordo com FREIRE et al. ${ }^{10}$, no Rio Grande do Sul, F. hepatica ocorre em ovinos, bovinos e sulnos, sendo prevalente nos ovinos. Segundo COSTA et al. ${ }^{8}$ essa espécie de trematódeo já foi assinalada em bovinos do
Rio Grande do Sul, Santa Catarina, Paraná, São Paulo, Rio de Janeiro e Minas Gerais; em bubalinos do Paraná e São Paulo; em ovinos do Rio Grande do Sul, Paraná e Rio de Janeiro; em caprinos do Paraná; em suínos do Rio Grande do Sul, Paraná, Sảo Paulo e Brasil Central; em cẩes e eqüinos no Paraná.

Estudos brasileiros sobre a epidemiologia da Fasciolose hepática foram publicados por UENO et al. ${ }^{14}$ para o Rio Grande do Sul, e UETA ${ }^{15}$ e AMATO et al. ${ }^{4}$ para São Paulo, regiăo do Vale do Paraíba; todos, entretanto, nảo mencionam o parasitismo em eqüinos.

$O$ diagnóstico da presença de F. hepatica no hospedeiro vertebrado vivo pode ser realizado por métodos sorológicos ou pelo exame de fezes (SERRA FREIRE ${ }^{12}$ ). Atualmente na Veterinária brasileira a técnica mais utilizada $e ́$ a da filtraçäo sequencial das fezes em tamis (DENNIS et al. ${ }^{9}$; GIRĀO \& UENO ${ }^{11}$; AMATO et al. ${ }^{4}$; SERRA FREIRE \& NUERNBERG ${ }^{13}$ ).

\section{2- MATERIAL E MÉTODOS}

Todas as amostras de fezes de eqüinos que foram

a. Médico Veterinário, MSc. Parasitologia, Laboratório de Apoio a Pesquisa Animal $/$ LAPA - Ministério da Agricultura / SC.

b. MV., MSc, DSc., Protessor Adjunto do Curso de PS\$-Graduaçăo em Medicina Veterinária - Parasitologia Veterinária / Universidade Federal Rural do Rio de Janeiro, 23.851, Seropédica, ttagual, Ru, Bolsista do CNPq. 
remetidas para o Laboratório de Diagnóstico do Laboratório de Apoio à Pesquisa Animal - LAPA/MA, sediado em Florianópolis, desde janeiro de 1977, foram examinadas com o objetivo de identificar ovos de F. hepatica.

Do Vale do Itajat, 132 amostras colhidas por veterinários e/ou proprietários rurais, acondicionadas individualmente em sacos plásticos, identificadas e transportadas, chegaram ao Laboratório em caixas de isopor com gelo.

Em agosto de 1991 foram coletadas amostras de fezes de quatro eqüinos suspeitos de parasitismo por helmintos de um plantel de 50 criados em Quilombo Velho, municipio de São José. Os animais eram três fêmeas e um macho inteiro, todos mestiços, com idade variando entre sete e oito anos e manejados semi-extensivamente. As amostras de fezes foram remetidas pela Companhia Integrada de Desenvolvimento Agrícola de Santa Catarina, CIDASC, e relatava a morte de um dos animais sem ter havido necrópsia do mesmo.

As fezes foram processadas individualmente pela filtraçâo sequencial em tamis de $250,150,80$ e $37 \mu \mathrm{m}$ de malha; o sedimento retido no último tamis foi suspendido em água destilada, e adicionado gotas de solução de verde metila. Esse material foi examinado entre lâmina e lamínula, preparando-se tantas montagens quantas fossem necessárias para examinar ao microscópio ótico toda a alfquota das fezes processadas (SERRA FREIRE \& NUERNBERG ${ }^{13}$ ).

\section{3- RESULTADOS E DISCUSSĀO}

Ovos de F. hepatica nas fezes da égua Nadir, um dos quatro animais suspeitos de helmintose conseqüente a emagrecimento progressivo, perda da capacidade de trabalho e redução do apetite, foram constatados. Esses ovos mediam 0,13 a $0,145 \mathrm{~mm}$ de comprimento por 0,07 a $0,09 \mathrm{~mm}$ de largura, apresentando operculo, massa embrionária ocupando todo o interior e coloração castanho amarelado (Fig. 1). Houve identificação do parasito pelos autores e confirmação diagnóstica pela Delegacia Federal do Ministério da Agricultura em Santa Catarina, também através de ovoscopia. Na propriedade onde se encontrou a égua parasitada por F. hepatica, existiam ruminantes parasitados com comprovação por ovoscopia a mais de cinco anos.

Das citaçōes de ocorrência de $F$. hepatica em eqüinos no Brasil, somente uma foi publicada (BUSETT) et al. ${ }^{5}$ ) com registro no Estado do Paraná; as demais cita-

\section{$-$}

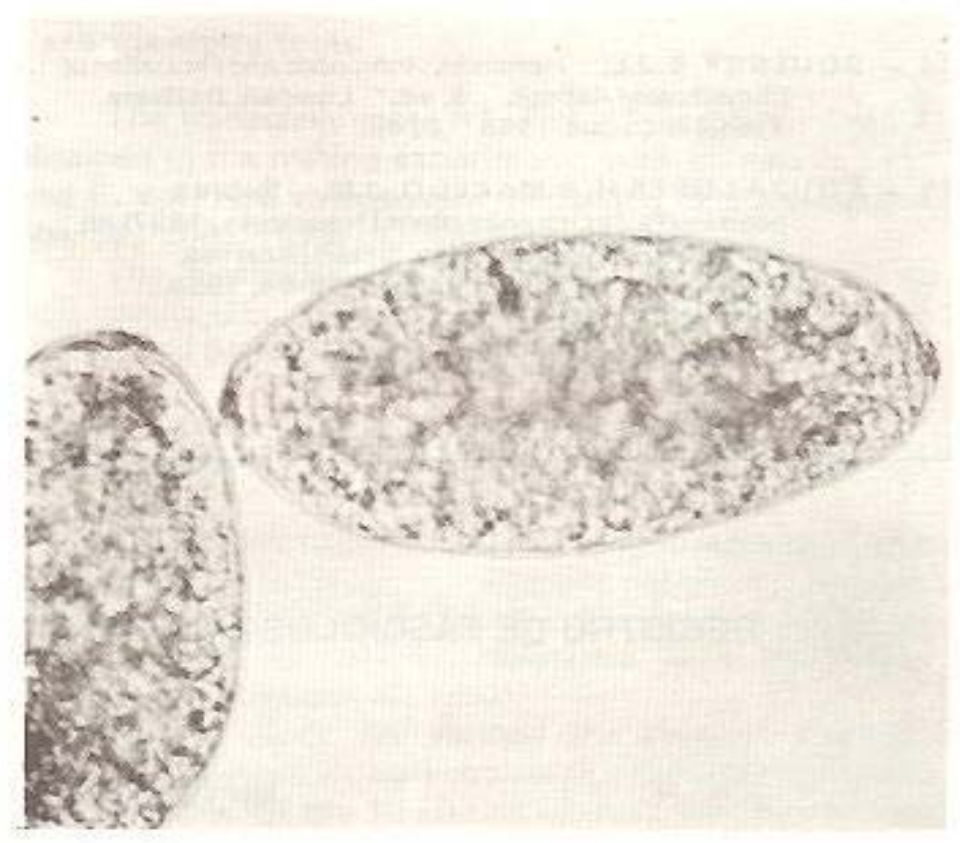

FIGURA 1 - Fotomicrografta de ovoz de Fasciola hepatica (400x)

çōes aconteceram em congressos e não foram publicadas, inclusive a inusitada referência de asininos parasitados por F. hepatica em Maranguape, Ceará (BUSETTI et al. 6 \%. Foi ainda BUSETTI7, em tese de concurso para Professor Titular na Universidade Federal do Paraná, quem listou 55 municipios do Estado do Paraná com a ocorrência de Fasciolose Hepática Eqüina. Nos oito anos desse trabalho, a autora investigou 310 propriedades rurais, das quais $173(55,81 \%)$ apresentavam casos de helmintose nos eqüinos, em um total de 27 animais jovens e 418 adultos examinados, com percentuais de fasciolose de $33,3 \%$ nos jovens ( 9 potros) e $45,45 \%$ nos adultos ( 190 casos), cobrindo todas as regiōes geográficas do Paraná.

Fora do Brasil reconhece-se a Fasciolose Hepática como sério problema na eqüinocultura (ALCAINO et al. ${ }^{1,2}$; ALVES et al. ${ }^{3}$ ), mas sem nenhum paralelo ao quadro alarmante descrito por BUSETTI ${ }^{7}$ não configurado nos vizinhos Estados de Santa Catarina, São Paulo e Mato Grosso do Sul (COSTA et al. ${ }^{8}$; AMATO et al. ${ }^{4}$; SERRA FREIRE \& NUERNBERG ${ }^{13}$ ).

A comprovaçāo da fasciolose eqüina no município de São José é o primeiro registro para o Estado de Santa Catarina, e surge a necessidade de investigaçăo especifica para avaliar o problema.

NUERNBERG, S. \& FREIRE, N.M. da S. Horse fasciolosis hepatica in Santa Catarina State, Brazil. Semina: Cl. Agr., Londrina, v. 13, n. 1, p. 41.43 , mar. 1992.

\section{ABSTRACT}

Since 1977, 132 horses of Itajail Valley, Santa Catanina State, Brasil, have been examined. In 1991 the authors describe a case of Fascioliasis by Fasciola hepatica in a temale horse of approximately eight years of age, breading in Săo José Municipality. This has been the first time this parasite was registered in the State of Santa Catarina, Brasil.

KEY-WORDS: Fasciola hepatica, horse, faeces exam, Itajal Valley.

\section{REFERENNCIAS BIBLIOGRAFICAS}

1. ALCAINO, H.; GORMAN, T.; GUEVARA, G.; FERNANDEZ, J. Distomatosis y parasitosis del intestino grueso de equinos de la $1^{\text {al }}$ zona Centro-Sul de Chile. Arch. Mod. Vot, 15 : 23-35, $1983 a$.
2. ALCAINO, H.; GORMAN, T.; PHILLIPS, J. Distomatosis en equinos fina sangre de carrera en haras e hipódromo de las reglones Ve Metropolltana de Chlle. Parasitol. al Dia, 7 : $37-40,1983 b$. 
3. ALVES, R.M.R.; VAN RENSBURG, L.J.; VAN WYK, J.A. Fasciola hepatica in horses in the Republic of South Africa: a single natural case of $F$. gigantica and the fallure to infest ten horses elther with $F$. hepatica or F. gigantica. Onderst. J. Vet Res. $55: 157-163,1988$.

4. AMATO, S.8.; REZENDE, H.E.B.; GOMES, D.C.; SERRA FREIRE, N.M. Epidemiology of Fasciola hepatica Infectlon in the Parafba River Valley, Sáo Paulo, Brazil. Vet Parasitol., 22: 275-284.

5. BUSETTI, T.E.; PASKE, A.; RUIZ, M.C.E.; THOMAZ SOCCOL, V. Fasciola hepatica em Equus caballus. Arq. Bras. Med. Vet. ZOOL, 35(2): 193-196, 1983a.

6. BUSETTI, T.E.; THOMAZ SOCCOL, V.; SA, J.E.P.C.; RUIZ, M.C.E. Equus asinus infostado naturalmente por Fasciofa hepatica. CONGRESSO DA FEDERAÇĀO LATINOAMERICANA DE PARASTOLOGLA, 6, Săo Paulo, 1983. Anais.. Săo Paulo, 1983b. p. 75.

7. BUSETTI, T.E. Contribuiçáo ao estudo da Fasciola hepatica Linaeus, 1758 (Tremaloda: Fasciolidae) no Estado do Parana. Brasil. Curitiba: Universidade Federal do Paraná, 1985.

Tese. Professor Thtular - Universidade Federal do Paraná.

8. COSTA, H.M.A.; LEITE, A.C.R.; GUIMARÃES, M.P.; LIMA, W.S. Distribuição dos Helmintos Parasitos de Animais Domésticos no Brasil. Arq. Bras. Meo. Vet. Zoot., 38(4): 465-579, 1986.
9. DENNS, W.R.; SIDNEY, W.M.; SWANSON, L.E. A noW laboratory and field diagnostic test for fluke ova in taeces. J. Am, Vet Med. Assoc, 124: 47-50, 1954.

10. FREIRE, J.J.; OLIVEIRA, C.M.B.; GONZALES, J.C. Fauna Parasftáris Riograndense. Arq. Fac. Vet UFRGS, Is: $19-59,1990$.

11. GIRÃO, E.S. \& UENO, H. Técnica de quatro tamises para o diagnóstico coprológico quantitativo da Fasciolose dos ruminantes. Pesq. Agropec Bras., 20: 905-912, 1985.

12. SERRA FREIRE, N.M. Fasclolose Hepática em História Natural das Doenças Parasitárias Priorltárias. Revista IICA (prelo), 1991.

13. SERRA FREIRE, N.M. \& NUERNBERG, S. Dispersăo geopolticica da ocorréncia de Fasciola hepatica no Estado de Santa Catarina, Brasil. Memo. Inst. Oswakdo Crus, 86 (Supl.)(prelo), 1990.

-14. UENO, H.; GUTIERREZ, V.C.: MATTOS, M.J.T,; MULLER, G. Fascioliasis problems in ruminants in Rio Grande do Sul, Brasil. Vet. Parasitol., 11: 185-191, 1982.

15. UETA, M.T. Infecção experimental de Lymnaea columella por Fasciola hepatica. Rev. Saúde Pübl. S. Paulo, 14: $43-57,1980$.

Recebido para publicaçắo en 10/6/1991 